\title{
Development of Corn-Oil Ester and Water Mixture Phase Change Materials for Low Temperature Refrigeration Applications
}

\author{
I Made Rasta, I Nyoman Suamir \\ Mechanical Engineering Department, Bali State Polytechnic \\ Kuta Selatan, Badung, Bali, 80364, Indonesia \\ maderasta@pnb.ac.id
}

\begin{abstract}
This study focuses on development of corn-oil ester and tap water mixtures as novel solid-liquid phase change material (PCM) candidates for low temperature refrigeration applications with product temperature between $-20{ }^{\circ} \mathrm{C}$ and $\mathbf{- 1 0}$ ${ }^{\circ} \mathrm{C}$. Thermal properties of both tap water and its mixture with corn-oil ester were tested by DSC and T-history methods. The test results showed that freezing and melting temperatures of tap water were $0{ }^{\circ} \mathrm{C}$ and phase transition temperatures of the mixtures were lower than those of individual tap water. The results indicated that corn-oil ester in the mixtures as a nucleate agent was able to lower the freezing point and to trigger ice nucleation in tap water which could diminish its super-cooling. The PCM candidates were found to have excellent thermal properties that could fulfill requirements of latent heat thermal energy storage systems used for low temperature refrigeration applications.
\end{abstract}

Keywords - corn-oil ester, phase change materials, thermal energy storage, low temperature refrigeration.

\section{INTRODUCTION}

Thermal energy storage (TES) systems could potentially provide energy savings, which in turn could reduce environmental impact related to energy use [1]. One way of storing heat is by using latent heat of phase change of a substance, usually from solid to liquid, as it can exhibit high latent heat of phase change and has attracted much interest as possible heat thermal storage [2]. Latent heat storage using PCMs is one of the most efficient methods of storing thermal energy [3]. PCMs have the advantages of high energy storage density and small temperature variation during phase change process [4]. They have been applied to increase the TES capacity of different systems [5]. In general, PCM are classified into organic compounds and inorganic compounds $[6,7]$. Organic PCMs are very important class materials because of their unique thermal properties such as congruent melting process and narrow melting-freezing temperature ranges $[8,9]$.

Selections of PCMs with suitable phase change temperatures are critical [10]. In order to obtain a desired phase change temperature, eutectics and mixtures can be formulated. This makes PCMs attractive in many applications [11]. In addition, the combination of nucleating agent within a
PCM is considered as a solution to minimize super-cooling [12].

The main requirements of a PCM from material point of view are, of course, high phase change enthalpy and suitable phase change temperature which is depending on the applications [13]. A PCM should have freezing-melting temperatures that can easily be adjusted [14]. Its melting temperature should be laying in a practical range of operation. Furthermore, it should be melting congruently with minimum degree of super-cooling, chemically stable, low in cost, nontoxic and non-corrosive [15].

To date, the best-known PCM is water. It has very good thermal properties such as reliability, low cost, high specific heat, high density, high latent capacity of $335 \mathrm{~kJ} / \mathrm{kg}$ and safe [16]. Technology using water as PCM is ready for use and available commercially. Unfortunately, for applications at temperatures below $0{ }^{\circ} \mathrm{C}$ water is not suitable [17]. Water also has a big degree of super-cooling during solidification process [18]. In some applications, degree of super-cooling can have major effect on a system performance [19]. In order to make water applicable as PCMs at temperatures below $0{ }^{\circ} \mathrm{C}$, nucleation agent could be added to trigger heterogeneous nucleation. This could also eliminate the super-cooling of water [20].

The main objective of this paper is to develop phase change material candidates for low temperature refrigeration applications. The PCM candidates were made by mixing cornoil ester which worked as nucleation agent. Corn-oil ester and water solutions to be investigated are applicable for low temperature refrigeration systems of product temperatures between $-20{ }^{\circ} \mathrm{C}$ until $-10{ }^{\circ} \mathrm{C}$. The solutions contain only small portion of corn oil ester. Larger part of the solutions is water which makes them become strong PCM candidates for low temperature refrigeration applications. Moreover, corn-oil ester also contains various types of fatty acids which have many superior properties as organic PCM materials [21-24]. Fatty acids are also derivatives of materials that are readily found in nature such as vegetable oils and labeled as bio-based materials [25]. However, fatty acid ester is more expensive compared with corn-oil ester. Another advantage is that cornoil ester offers a continuous supply $[26,27]$. 


\section{MATERIALS AND METHODS}

\section{A. Materials}

Materials used in this study were tap water and natural-oil ester as nucleating agent resulted from esterification of corn oil. The natural oil ester is then called as corn-oil ester. It contains methyl esters as its major chemical composition. Methyl ester is a small ester with single carbon chain. Small esters are soluble in water. In addition, solubility of small ester in water such as corn oil ester can also be explained that certain acid molecules of ester in water solution having - $\mathrm{OH}$ cluster are ionized by releasing hydrogen atom to make ion $\mathrm{H}+$. Even though esters cannot hydrogen bond with themselves but esters can hydrogen bond with water molecules. Individual positive hydrogen atom in a water molecule can be attracted to one of the single pairs on one of the oxygen atoms in an ester for a hydrogen bond to be formed. Moreover, there is also dispersion forces and dipoledipole attractions between the ester and the water molecules which releases energy. This helps to supply energy required to separate water molecule and ester molecule from others before they can mix together $[6,28]$. This certainly explains why corn oil ester dissolves in water.

The corn-oil esters were chosen as nucleating agents for the purpose of obtaining a low cost PCM which was considered as one important factor for the scale of PCM applications. At present, the market price of fatty acid esters is relatively high. This is because of the cost of producing the fatty acid esters is higher than that of corn oil esters due to production line of fatty acid ester includes purification process. While the corn-oil esters can be used without further purification.

\section{B. Preparation of corn-oil ester in water eutectic mixture as PCM}

Establishing energy conservation at temperature below 0 ${ }^{\circ} \mathrm{C}$ through implementation of phase change material (PCM), two type substances can be mixed in their eutectic proportion to attain the lowest eutectic temperature, that is the phase change temperature. In this research, to reduce phase change temperature of pure water, corn-oil ester was applied as a dispersed phase and tap water as a continuous phase of the solution. The solutions were prepared at different concentrations (\% volume) of corn-oil ester in water, namely: $15 \%, 20 \%$ and $25 \%$. Other concentrations such as $5 \%, 7.5 \%$, and $10 \%$ have also been investigated for medium temperature refrigeration applications [29] but they are not included in this paper. For testing purposes, volume of each PCM sample was prepared for $10 \mathrm{ml}$ and inserted in a glass tube.

Chemical composition of corn-oil ester was individually tested with Gas Chromatography Mass Spectrometry (GCMS). The test method comprised analysis of corn oil ester which was performed on a GC-MS Shimadzu type QP 2010 with a split/split less injector. Separations were achieved using an Agilent J\%W DB-1 capillary column (30 m $\times 0.25 \mathrm{~mm}$ ID). Helium was used as carrier gas with initial pressure of 12.0 $\mathrm{kPa}$, constant linear velocity of $26.6 \mathrm{~cm} / \mathrm{sec}$, column flow: $0.54 \mathrm{~mL} / \mathrm{minute}$ and a split ratio of $1: 21.2$. The injector temperature was $300{ }^{\circ} \mathrm{C}$. The oven temperature was programmed at $50{ }^{\circ} \mathrm{C}$ with hold for 10 minutes and increased to $280{ }^{\circ} \mathrm{C}$ at a rate of $5{ }^{\circ} \mathrm{C} /$ minute and hold at the final temperature for 49 minutes. MS parameters: samples were analyzed in the full scan mode with a scan speed of 2,000 atomic mass unit (amu)/sec and a mass range of $28-610 \mathrm{~m} / \mathrm{z}$; interface and ion source temperatures were $250{ }^{\circ} \mathrm{C}$ and $305^{\circ} \mathrm{C}$ respectively. The MS corn oil ester peaks were identified by comparing their retention time with NIST62 and WILEY229 library.

The GCMS test results are presented in Table I. The table shows that corn-oil ester is composed mainly by methyl esters of $38.54 \%$. The oil ester also contains benzene $(17.45 \%), 1,3-$ cyclohexadiene $(8.29 \%)$, beta-sesquiphellandrene $(23.83 \%)$ and others of about $11.89 \%$. Esters are polar molecules that have a very important role on the solubility of corn oil in water.

TABLE I. CHEMICAL COMPOSITION OF COMMERCIAL CORN-OIL ESTER

\begin{tabular}{lcc}
\hline \multicolumn{1}{c}{ Component name } & Formula & $\begin{array}{c}\text { Area } \\
\text { (\%) }\end{array}$ \\
\hline 3-Isopropoxy-1,1,1,7,7,7-hexamethyl- & $\mathrm{C}_{18} \mathrm{H}_{52} \mathrm{O}_{7} \mathrm{Si}_{7}$ & 0.61 \\
3,5,5-tris (trimethylsiloxy) & & \\
Benzene, 1-(1,5-dimethyl-4-hexenyl) & $\mathrm{C}_{15} \mathrm{H}_{22}$ & 17.45 \\
1,3-Cyclohexadiene, 5-(1,5-dimethyl-4- & $\mathrm{C}_{15} \mathrm{H}_{24}$ & 8.29 \\
hexenyl) & & \\
Copaene & $\mathrm{C}_{15} \mathrm{H}_{24}$ & 0.28 \\
8-Nonenoic acid, 5,7-Dimethylene-, & $\mathrm{C}_{12} \mathrm{H}_{18} \mathrm{O}_{2}$ & 0.50 \\
methyl ester & & \\
Cyclohexene, 1-methyl-4-(5-methyl-1- & $\mathrm{C}_{15} \mathrm{H}_{24}$ & 8.45 \\
methylene-4-hexenyl) & & \\
Dodecanoic acid, methyl ester & $\mathrm{C}_{13} \mathrm{H}_{26} \mathrm{O}_{2}$ & 10.92 \\
Beta-sesquiphellandrene & $\mathrm{C}_{15} \mathrm{H}_{24}$ & 23.83 \\
Hexadecanoic acid, methyl ester & $\mathrm{C}_{17} \mathrm{H}_{34} \mathrm{O}_{2}$ & 13.28 \\
3-Butoxy-1,1,1,7,7,7-hexamethyl-3,5,5- & $\mathrm{C}_{19} \mathrm{H}_{54} \mathrm{O}_{7} \mathrm{Si}_{7}$ & 0.68 \\
tris (trimethylsiloxy) & & \\
Dodecanoic acid, (2,2-dimethyl-1,3- & $\mathrm{C}_{18} \mathrm{H}_{34} \mathrm{O}_{4}$ & \\
dioxolan-4-yl) methyl ester & $\mathrm{C}_{22} \mathrm{H}_{42} \mathrm{O}_{4}$ & 2.95 \\
Hexadecanoic acid, (2,2-dimethyl-1,3- & $\mathrm{C}_{23} \mathrm{H}_{44} \mathrm{O}_{4}$ & \\
dioxolan-4-yl) methyl ester & & \\
2-Heptadecanone, 1- (2,2-dimethyl-1,3- & & \\
dioxolan-4-yl) methoxy & & \\
Anodendroside G, monoacetate & $\mathrm{C}_{32} \mathrm{H}_{42} \mathrm{O}_{11}$ & 0.48 \\
9-Octadecenoic acid (Z), methyl ester & $\mathrm{C}_{19} \mathrm{H}_{36} \mathrm{O}_{2}$ & \\
7-Hexadecenoic acid, methyl ester & $\mathrm{C}_{17} \mathrm{H}_{32} \mathrm{O}_{2}$ & 6.21 \\
9-Octadecenoic acid, methyl ester & $\mathrm{C}_{19} \mathrm{H}_{36} \mathrm{O}_{2}$ & \\
Cyclopropanebutanoic acid & $\mathrm{C}_{25} \mathrm{H}_{42} \mathrm{O}_{2}$ & 1.38 \\
$\begin{array}{l}\text { Oxiraneoctanoic acid, 3-octyl, methyl } \\
\text { ester, trans }\end{array}$ & $\mathrm{C}_{19} \mathrm{H}_{36} \mathrm{O}_{3}$ & \\
Heptasiloxane, hexadecamethyl ester & $\mathrm{C}_{16} \mathrm{H}_{48} \mathrm{O}_{6} \mathrm{Si}_{7}$ & 1.63 \\
Octadecanoic acid, methyl ester & $\mathrm{C}_{19} \mathrm{H}_{38} \mathrm{O}_{2}$ & 1.99 \\
Heptasiloxane, hexadecamethyl ester & $\mathrm{C}_{16} \mathrm{H}_{48} \mathrm{O}_{6} \mathrm{Si}_{7}$ & 1.06 \\
\hline & & \\
& & \\
\hline
\end{tabular}

\section{DSC and T-history thermal analyses}

Thermal properties of the PCM candidates (of corn-oil ester in water mixtures) were measured by differential scanning calorimeter (Perkin Elmer Jade DSC). The properties included melting and freezing temperatures and latent heat of melting and freezing. The analyses were performed at temperatures between $25{ }^{\circ} \mathrm{C}$ and $-100{ }^{\circ} \mathrm{C}$ for cooling and from $-100{ }^{\circ} \mathrm{C}$ to $25^{\circ} \mathrm{C}$ for heating at $2{ }^{\circ} \mathrm{C}$ per minute of cooling and heating rate. The analyses were also performed under a constant stream of nitrogen gas at flow rate of $20 \mathrm{~mL}$ per minute. The temperature accuracy was $\pm 0.01{ }^{\circ} \mathrm{C}$ and heat flow repeatability was $0.2 \mu \mathrm{W}$. A $30 \mathrm{mg}$ sample of PCM 
candidate was sealed in an aluminum pan. The melting and crystallization points were taken as onset temperatures. The latent heat of PCM candidates was determined by numerical integration of the area of peak thermal transition.

Even though phase change temperatures of the solutions can be measured by the DSC system, the specimen used in DSC is very small (of about $10-30 \mathrm{mg}$ ) which is not applicable for practical use especially for samples that contain water with high degree of super-cooling [30,31]. Whereas degree of super-cooling is an important parameter for PCMs. In this research, phase change temperatures and degree of supercooling of the PCM candidates were tested by using T-history method which is considered more suitable for this application. Detailed method and equipment used for the T-history measurement have been published and reported in [29].

\section{RESULTS AND DISCUSSION}

\section{A. Super-cooling analysis}

Super-cooling occurs when the temperature of a liquid is lowered below its freezing point without becoming a solid [32]. Fig. 1 shows that tap and mineral water was super-cooled to reach $-7.5{ }^{\circ} \mathrm{C}$ and $-8.5{ }^{\circ} \mathrm{C}$ respectively before the ice formation process started. The ice crystallization process involves combination of nucleation and growth of ice crystals within a crystalline structure. Investigation on pure water reported in [33] stated that pure water which does not contain nucleation of ice particle can withstand its liquid condition during super-cooled state down to as low as $-42{ }^{\circ} \mathrm{C}$ before freezing homogenously. Transformation of water into crystal requires nucleus as crystallization trigger. It takes appropriate incorporation of molecules in a sufficient size to provide a nucleus for crystal growth [34]. Ice crystal formation occurs after nucleation, at which the water molecules join the already formed nuclei.

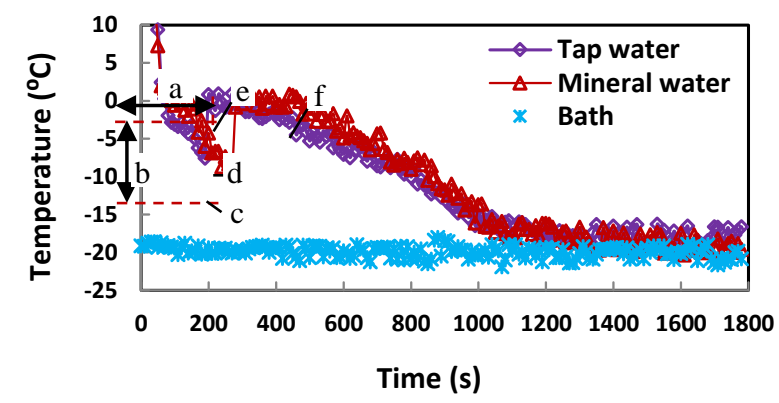

a. Ice nucleation delay, b. Super-cooling degree, c. Ice nuclei, d. Growth ice crystal, e. Initial formation of solid ice layer, f. Complete formation of solid ice layer

Fig. 1. Temperature in the center of samples at bath temperature of $-20{ }^{\circ} \mathrm{C}$

Fig. 2 shows that PCM candidates with different concentration of corn-oil ester are able to initiate formation of ice nuclei quickly at somewhat higher temperature than its approaching freezing-point of the solution. The additions of $15 \%, 20 \%$ and $25 \%$ of corn-oil ester in the PCM candidates can decrease tap water freezing point to $-10{ }^{\circ} \mathrm{C},-15^{\circ} \mathrm{C}$ and $19.5{ }^{\circ} \mathrm{C}$ respectively. They can also reduce super-cooling degree to $0.75 \mathrm{~K}, 0.4 \mathrm{~K}$ and $0 \mathrm{~K}$ respectively. Water molecules, which merge with nuclei formed in the solution, increase the crystal growth rate until at a stable state of the solution. The stable state of the solution is achieved when no more crystal is being formed. The addition of corn-oil ester as solute particle into the tap water as solvent produce some ions that contribute to intermolecular force between solvent and solute particles.

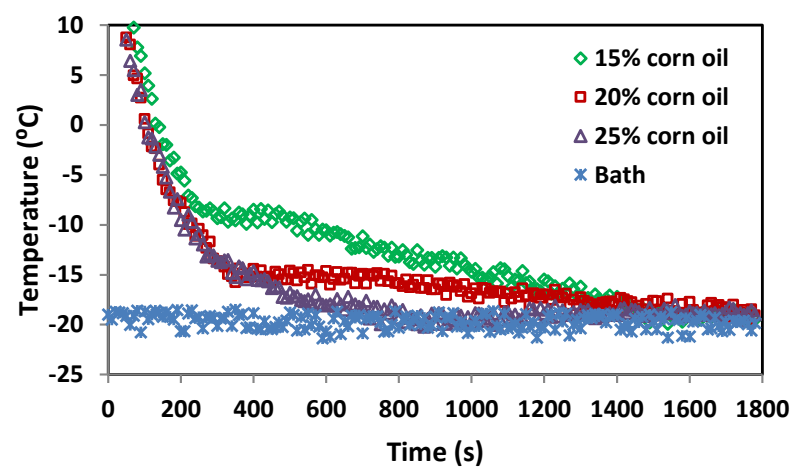

Fig. 2. Cooling process of $15 \%$; $20 \%$; and $25 \%$ corn-oil ester in tap water solutions at bath temperature of $-20{ }^{\circ} \mathrm{C}$

During cooling process, the pulling force between solvent and solute particles release more heat hence the freezing point of the solution is lowered. Therefore, corn-oil ester solution is able to reduce or even eliminate super-cooling due to: (i) faster nucleation and (ii) lower freezing point. The role of corn-oil ester solution, therefore, is able to eliminate and to reduce freezing point in some extent according to solution concentrations, as shown in Table II.

TABLE II. THERMAL PROPERTIES OF THE PCM CANDIDATES, DSC TEST RESULTS

\begin{tabular}{|c|c|c|c|c|}
\hline \multirow[b]{3}{*}{$\begin{array}{l}\text { Samples } \\
\text { (Vol. \%) }\end{array}$} & \multicolumn{4}{|c|}{ DSC } \\
\hline & \multicolumn{2}{|c|}{ Heating process } & \multicolumn{2}{|c|}{ Cooling process } \\
\hline & $\begin{array}{l}\text { Melting } \\
\text { temp. } \\
\left(\mathrm{Tm},{ }^{\circ} \mathrm{C}\right)\end{array}$ & $\begin{array}{l}\text { Latent heat of } \\
\text { melting } \\
\left(\Delta \mathrm{H}_{\mathrm{m}}, \mathrm{J} / \mathrm{g}\right)\end{array}$ & $\begin{array}{l}\text { Freezing } \\
\text { temp. } \\
\left(\mathrm{T}_{\mathrm{f}},{ }^{\circ} \mathrm{C}\right)\end{array}$ & $\begin{array}{c}\text { Latent heat of } \\
\text { freezing } \\
\left(\Delta \mathrm{H}_{\mathrm{f}}, \mathrm{J} / \mathrm{g}\right)\end{array}$ \\
\hline Tap water & 0 & 297.4346 & -19.5 & -102.3901 \\
\hline Mineral water & - & - & - & - \\
\hline $15 / 85(\mathrm{O} / \mathrm{W})$ & -10.5 & 124.9906 & -27 & -113.1630 \\
\hline $20 / 80(\mathrm{O} / \mathrm{W})$ & -15 & 107.3320 & -33 & -109.7693 \\
\hline $25 / 75(\mathrm{O} / \mathrm{W})$ & -20 & 85.0207 & -36 & -91.7049 \\
\hline
\end{tabular}

$\mathrm{O} / \mathrm{W}=$ Corn-oil ester in water

\section{B. Thermal properties of the PCM candidates}

In order to compare thermal properties and phenomena in melting and freezing processes of the PCM candidates, the DSC curve for melting and freezing processes of tap water is also presented in this paper as shown in Fig. 3. The figure shows that there is a high degree of super-cooling, as indicated by two intense exothermic peaks during cooling cycles. The melting and freezing temperatures of tap water resulted from DSC were $0{ }^{\circ} \mathrm{C}$ and $-19.5^{\circ} \mathrm{C}$ respectively, and the latent heat of melting and freezing were $297.4 \mathrm{~J} / \mathrm{g}$ and $102.4 \mathrm{~J} / \mathrm{g}$ respectively. It is noteworthy that, whatever the sample size, ice melts at $0{ }^{\circ} \mathrm{C}$ [35]. On the contrary, freezing occurs at different temperatures, depending on the water sample size [36]. From nucleation theory, it has been shown that the 
smaller the volume, the lower the freezing temperature. For bulk water, freezing occurs at $-14{ }^{\circ} \mathrm{C}$ for a volume of $1 \mathrm{~cm} 3$ and at around $-24{ }^{\circ} \mathrm{C}$ for a volume of $1 \mathrm{~mm}^{3}$, while for microsized droplets $\left(1 \mu \mathrm{m}^{3}\right)$ freezing is found around $-39{ }^{\circ} \mathrm{C}$ [37]. The energy released during the freezing process is evidenced on the DSC result as an exothermic peak with imperfect bell shape when compared with melting process.

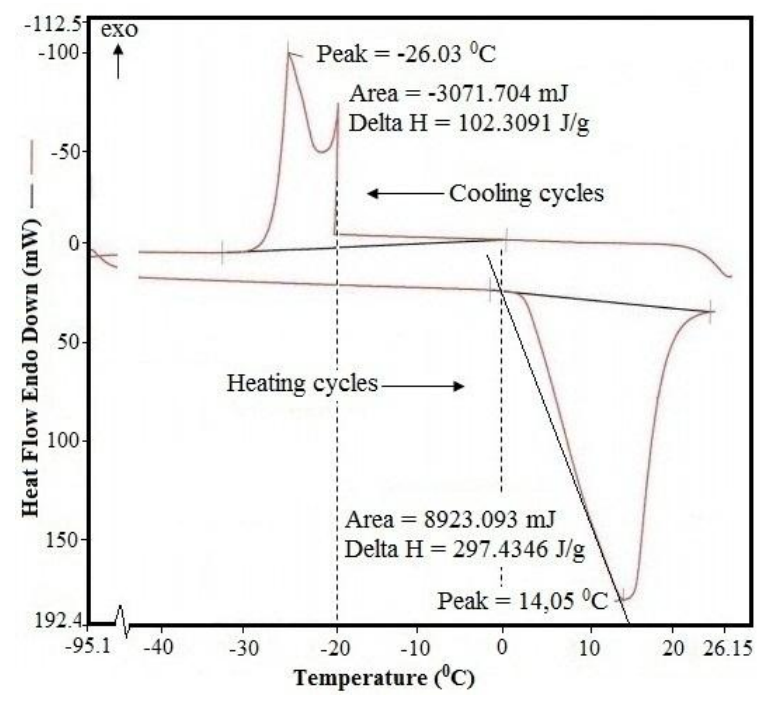

Fig. 3. DSC curves of tap water during heating and cooling processes

The temperature difference between two exothermic peaks during cooling cycles may be correlated to the amount of super-cooling degree which depends on surface conditions, cooling rate, liquid volume and nucleate agent [38]. In the melting phenomenon there is no delay, all the water melts at the same temperature, i.e. $0{ }^{\circ} \mathrm{C}$, which is the thermodynamic equilibrium temperature between ice and water.

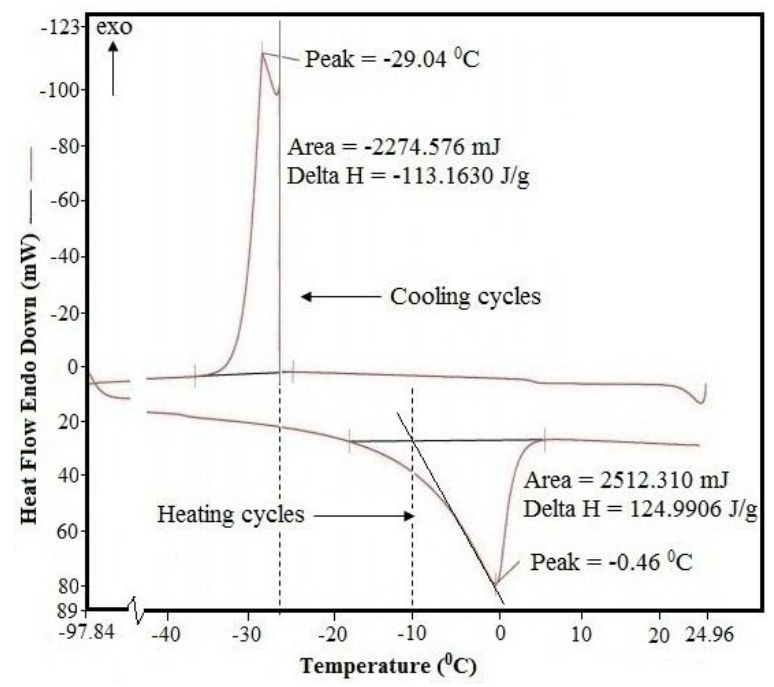

Fig. 4. DSC curves of $15 \%$ corn-oil ester in water (heating and cooling processes)

Thermal properties of PCM candidates which contain tap water and various compositions of corn-oil ester can be seen in Figs. 4-6. Fig. 4 shows thermal properties of PCM candidate with $15 \%$ corn-oil ester. From the figure it can be seen that the addition of $15 \%$ corn-oil ester into tap water still demonstrates the occurrence of super-cooling. Increasing the concentration of the corn-oil ester to $20 \%$ (Fig. 6) causes degree of super-cooling of the PCM solution decreases. Degree of super-cooling is totally disappeared as the concentration of corn-oil ester reaches $25 \%$. This is indicated by a perfect bell shape shown in Fig. 6 .

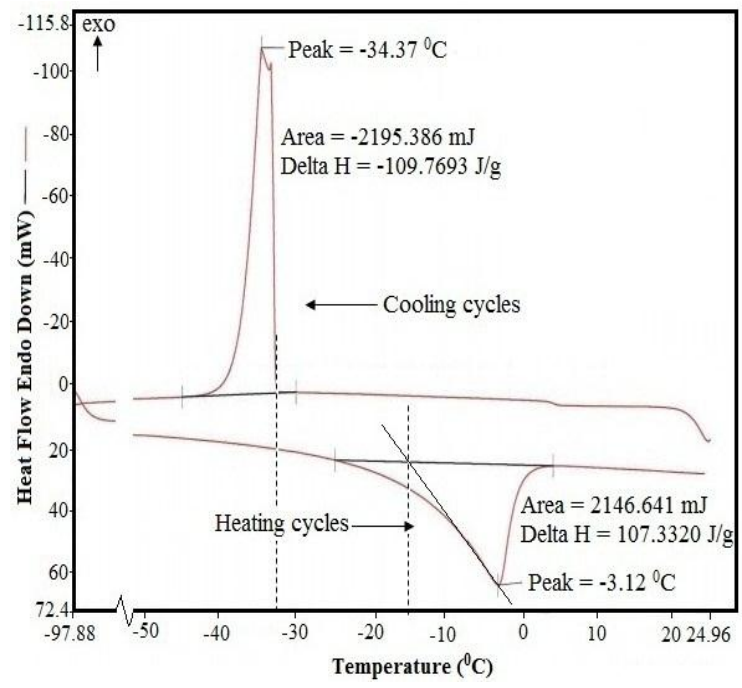

Fig. 5. DSC curves of $20 \%$ corn-oil ester in water (heating and cooling processes)

The results also show that a complete process of crystallization, which can be seen in Figs. 3-6, is very fast because with only one nucleus may initiate the solidification and simultaneously nucleation occurs. Therefore, a significant amount of energy is released in a very short time, and that is the reason why the first part of the exothermic freezing peak is so sharp. The freezing temperatures vary from one sample to another, because nucleation is a stochastic phenomenon.

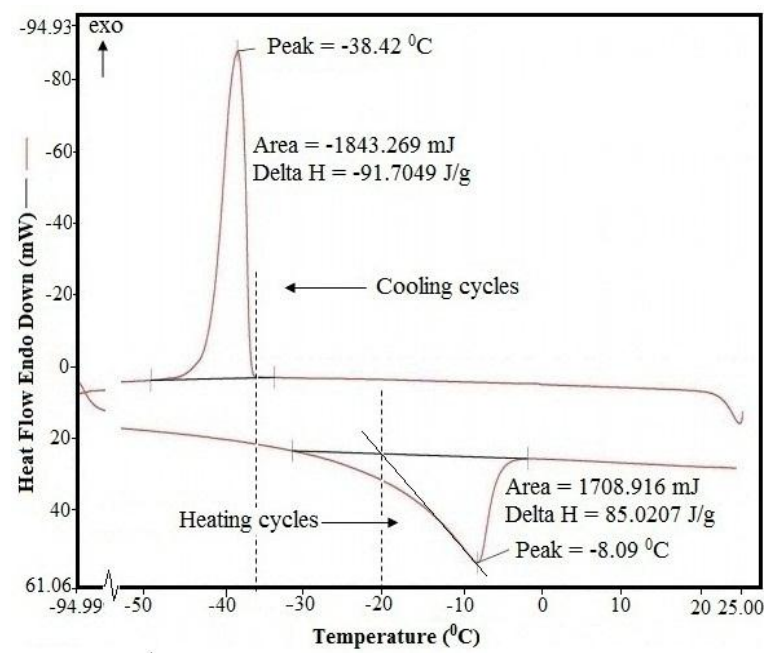

Fig. 6. DSC curves of $25 \%$ corn-oil ester in water (heating and cooling processes) 
Results of DSC and T-history test methods are also summarized in Table II and III. The table clearly shows that melting temperatures of the PCM candidates are lower than those of the tap and mineral water. Table III also shows freezing temperature of water obtained from T-history are 0 ${ }^{\circ} \mathrm{C}$. The melting and freezing temperatures of corn-oil ester in water solutions of concentration $15 \%, 20 \%$ and $25 \%$ (by volume) range from $-10{ }^{\circ} \mathrm{C}$ to $-20{ }^{\circ} \mathrm{C}$. While melting and freezing latent heat varies from $85-125 \mathrm{~J} / \mathrm{g}$ to $92-113 \mathrm{~J} / \mathrm{g}$ respectively. The results indicated that by increasing concentration of corn-oil ester in water solution can reduce melting temperature and minimize or even negate the supercooling. These properties make the solutions potential to be PCMs with large latent heat and suitable phase change temperatures for low temperature refrigeration applications. For discussion on methods to apply PCM as energy storage in freezer cabinet with low temperature refrigeration system has been reported in [39].

TABLE III. THERMAL PROPERTIES OF THE PCM, T-HISTRORY TEST RESULTS

\begin{tabular}{lcc}
\hline \multirow{3}{*}{$\begin{array}{l}\text { Samples } \\
\text { Vol. \%) }\end{array}$} & \multicolumn{2}{c}{ T-history } \\
\cline { 2 - 3 } & \multicolumn{2}{c}{ Cooling process } \\
\cline { 2 - 3 } & $\begin{array}{r}\text { Freezing temp. } \\
\left(\mathrm{T}_{\mathrm{f}},{ }^{\circ} \mathrm{C}\right)\end{array}$ & $\begin{array}{c}\text { Super-cooling } \\
\text { degree }(\mathrm{K})\end{array}$ \\
\hline Tap water & 0 & 7.5 \\
Mineral water & 0 & 8.5 \\
$15 / 85(\mathrm{O} / \mathrm{W})$ & -9.5 & 0.75 \\
$20 / 80(\mathrm{O} / \mathrm{W})$ & -15 & 0.4 \\
$25 / 75(\mathrm{O} / \mathrm{W})$ & -19.5 & 0 \\
\hline
\end{tabular}

\section{CONCLUSIONS}

Corn oil ester in tap water mixtures have been investigated for development of phase change materials (PCMs) as thermal energy storages that can be applied for low temperature refrigeration systems. DSC and T-history thermal analyses were applied in the investigation and it has been found that the water-based mixtures contain 15\%,20\% and $25 \%$ corn-oil ester have freezing temperatures of $-10{ }^{\circ} \mathrm{C},-15{ }^{\circ} \mathrm{C}$ and $-20{ }^{\circ} \mathrm{C}$ respectively. The investigation also found that the PCM candidates at test conditions have minimum or even without degree of super-cooling. Additionally, corn-oil ester and water offer a continuous supply and cheaper compared with fatty acid esters that frequently used for below $0{ }^{\circ} \mathrm{C}$ applications. These make the mixture of corn oil ester and water become applicable as low cost novel PCMs for low temperature refrigeration applications.

\section{ACKNOWLEDGMENT}

The authors acknowledge the financial support received from the Higher Education Directorate General of the Ministry of Education and Culture of the Republic of Indonesia.

\section{REFERENCES}

[1] Y. Yuan, N. Zhang, W. Tao, X. Cao, and Y. He, "Fatty acids as phase change materials: a review", Renew. Sustain. Energy Rev. 29, 2014, 482-498.
[2] M.M. Farid, A.M. Khudhair, S.A.K. Razack, and S. Al-Hallaj, "A review on phase change energy storage: materials and applications", Energy Convers. Manage. 45, 2004, 1597-1615.

[3] Z. Zhou, Z. Zhang, J. Zuo, K. Huang, and L. Zhang, "Phase change materials for solar thermal energy storage in residential buildings in cold climate", Renew. Sustain. Energy Rev. 48, 2015, 692-703.

[4] Y. Yuan, Y. Yuan, N. Zhang, Y. Du, and X. Cao, "Preparation and thermal characterization of capric-myristic-palmitic acid/expanded graphite composite as phase change material for energy storage", Mater. Lett. 125, 2014, 154-157.

[5] B. Zalba, J.M. Marin, L.F. Cabeza, and H. Mehling, "Review on thermal energy storage with phase change materials, heat transfer analysis and applications", Appl. Therm. Eng. 23, 2003, 251-283.

[6] R.K. Sharma, P. Ganesan, V.V. Tyagi, H.S.C. Metselaar, and S.C. Sandaran, "Developments in organic solid-liquid phase change materials and their applications in thermal energy storage", Energy Convers. Manage. 95, 2015, 193-228.

[7] W. Su, J. Darkwa, and G. Kokogiannakis, "Review of solid-liquid phase change materials and their encapsulation technologies", Renew. Sustain. Energy Rev. 48, 2015, 373-391.

[8] R. Al-Shannaq, M. Farid, S. Al-Muhtaseb, and J. Kurdi, "Emulsion stability and cross-linking of PMMA microcapsules containing phase change materials", Sol. Energy Mater. Sol. Cells 132, 2015, 311-318.

[9] Z. Zhou, Z. Zhang, J. Zuo, K. Huang, and L. Zhang, "Phase change materials for solar thermal energy storage in residential buildings in cold climate", Renew. Sustain. Energy Rev. 48, 2015, 692-703.

[10] J. Lei, J. Yang, and E.H. Yang, "Energy performance of building envelopes integrated with phase change materials for cooling load reduction in tropical Singapore", Appl. Energy 162, 2016, 207-217

[11] A Sharma, V.V. Tyagi, C.R. Chen, and D. Buddhi, "Review on thermal energy storage with phase change materials and applications", Renew. Sustain. Energy Rev. 13, 2009, 318-345.

[12] Y. Liu, X. Li, P. Hu, and G. Hu, "Study on the supercooling degree and nucleation behavior of water-based graphene oxide nanofluids PCM", Int. J. Refrigeration, 50, 2015, 80-86.

[13] G. Ferrer, A. Solé, C. Barreneche, I. Martorell, and L.F. Cabeza, "Review on the methodology used in thermal stability characterization of phase change materials", Renew. Sustain. Energy Rev. 50, 2015, 665685.

[14] S.E. Kalnaes, and B.P. Jelle, "Phase change materials and products for building applications: A state-of-the-art review and future research opportunities”, Energy Build. 94, 2015, 150-176.

[15] X.Q. Zhai, X.L. Wang, T. Wang, and R.Z. Wang, "A review on phase change cold storage in air-conditioning system: Materials and applications", Renew. Sustain. Energy Rev. 22, 2013, 108-120.

[16] T. Kousksou, A. Jamil, and Y. Zeraouli, "Enthalpy and apparent specific heat capacity of the binary solution during the melting process: DSC modeling", Thermochim. Acta 541, 2012, 31-41.

[17] A. Marques, G. Davies, G. Maidment, J. Evans, and I. Wood. "Novel design and performance enhancement of domestic refrigerators with themal storage", Appl. Therm. Eng. 63, 2014, 511-519.

[18] S.L. Braga, and J.J. Milón, "Visualization of dendritic ice growth in supercooled water inside cylindrical capsules", Int. J. Heat Mass Transfer 55, 2012, 3694-3703.

[19] R.A. Taylor, N. Tsafnat, and A. Washer, "Experimental characterization of sub-cooling in hydrated salt phase change materials", Appl. Thermal Eng. 93, 2016, 935-938.

[20] P. Zhang, X. Xiao, and Z.W. Ma, "A review of the composite phase change materials: Fabrication, characterization, mathematical modeling and application to performance enhancement", Appl. Energy 165, 2016, $472-510$.

[21] W. Lu, and S.A. Tassou, Characterization and experimental investigation of phase change materials for chilled food refrigerated cabinet applications, Appl. Energy, 112, 2013, 1376-1382.

[22] Y. Yuan, N. Zhang, W. Tao, X. Cao, and Y. He, "Fatty acids as phase change materials: A review", Renew. Sustain. Energy Rev. 29, 2014, 482-498. 
[23] D. Rozanna, T.G. Chuah, A. Salmiah, T.S.Y. Choong, and M. Sa'ri, "Fatty acids as phase change materials (PCMs) for thermal energy storage: a review", Int. J. Green Energy 1, 2004, 495-513.

[24] L.C. Liston, Y. Farnam, M. Krafcik, J. Weiss, K. Erk, and B.Y. Tao, "Binary mixtures of fatty acid methyl esters as phase change materials for low temperature applications", Appl. Thermal Eng. 96, 2016, 501507.

[25] K. Cellata, B. Beyhana, C. Güngörb, Y. Konukluc, O. Karahand,C. Dündare, and H. Paksoya, "Thermal enhancement of concrete by adding bio-based fatty acids as phase change materials", Energy and Build. 106, 2015, 156-163.

[26] A. Sharma, A. Shukla, C.R. Chen, and T.N. Wu, "Development of phase change materials (PCMs) for low temperature energy storage applications", Sustain. Energy Tech. Assess. 7, 2014, 17-21.

[27] H. Fauzi, H.S.C. Metselaar, T.M.I. Mahlia, M. Silakhori, and H.C. Ong, "Thermal characteristic reliability of fatty acid binary mixtures as phase change materials (PCMs) for thermal energy storage applications", Appl. Thermal Eng. 80, 2015, 127-131.

[28] J. Clark, Introducing Esters, 2016, Available at: http://www.chemguide. co.uk/organicprops/esters/background.html.

[29] I.M. Rasta, and I.N. Suamir, "The role of vegetable oil in water based phase change materials for medium temperature refrigeration", J. Energy Storage, 15, 2018, 368-378.

[30] E. Günther, S. Hiebler, H. Mehling, and R. Redlich, "Enthalpy of phase change materials as a function of temperature: required accuracy and suitable measurement methods", Int. J. Thermophys. 30, 2009, 1257 1269.
[31] H. Mehling, and L.F. Cabeza, "Heat and Cold storage with PCM - An up to date introduction into basics and applications", Berlin: Springer, 2008.

[32] L. Huang, E. Günther, C. Doetsch, and H. Mehling, "Subcooling in PCM emulsions - Part 1: Experimental, Thermochim”, Acta, 509, 2010, 93-99.

[33] B. Murray, "Homogeneous ice nucleation in water and aqueous solutions", Physical Chemistry Chemical Physics, 12, 2010, 1038010387.

[34] D. Fennema, W.D. Powrie, and E.H. Marth, Low Temperature Preservation of Foods and Living Matter, Marcel Dekker Inc., New York, 1973.

[35] M. Brun, A. Lallemand, J.F. Quinson, and C. Eyraud, "A new method for the simultaneous determination of the size and shape of pores: the thermoporometry", Thermochim. Acta 21, 1977, 59-88.

[36] C. Dalmazzone, and D. Clausse, "in Encyclopedic Handbook of Emulsion Technology”, Sjöblom J.(ed.), Marcel Dekker, New York, 2001, Chap., 14.

[37] C. Dalmazzone, C. Noïk, and D Clausse, "Application of DSC for emulsified system characterization", Oil \& Gas Sci. Tech. Rev. IFP 64, 2009, 543-555.

[38] S.L. Braga, and J.J. Milón, "Visualization of dendritic ice growth in supercooled water inside cylindrical capsules", Int. J. Heat Mass Transfer 55, 2012, 3694-3703.

[39] A.H. Raeisi, I.N. Suamir, and S.A. Tassou,'Energy storage in freezer cabinets using phase change materials", Proc. the 2nd International Cold Chain Conference, Paris, 2013, 8 pgs. 